\title{
Manual Dexterity in Schizophrenia-A Neglected Clinical Marker?
}

\begin{abstract}
Maxime Térémetz', Loïc Carment ${ }^{1}$, Lindsay Brénugat-Herne ${ }^{2,3}$, Marta Croca ${ }^{2,3}$, Jean-Pierre Bleton ${ }^{4}$, Marie-Odile Krebs ${ }^{2,3}$, Marc A. Maier ${ }^{1,5}$, Isabelle Amado ${ }^{2,3+}$ and Påvel G. Lindberg ${ }^{1,3 * t}$
\end{abstract}

${ }^{1}$ FR3636, CNRS, Université Paris Descartes, Sorbonne Paris Cité, Paris, France, ${ }^{2}$ SHU, Resource Center for Cognitive Remediation and Psychosocial Rehabilitation, Université Paris Descartes, Hôpital Sainte-Anne, Paris, France, ${ }^{3}$ INSERM U894, GDR3557 Psychiatrie, Université Paris Descartes, Sorbonne Paris Cité, Paris, France, ${ }^{4}$ Service de Neurologie, Fondation OPH de Rothschild, Paris, France, ${ }^{5}$ Université Paris Diderot, Sorbonne Paris Cité, Paris, France

Impaired manual dexterity is commonly observed in schizophrenia. However, a quantitative description of key sensorimotor components contributing to impaired dexterity is lacking. Whether the key components of dexterity are differentially affected and how they relate to clinical characteristics also remains unclear. We quantified the degree of dexterity in 35 stabilized patients with schizophrenia and in 20 age-matched control subjects using four visuomotor tasks: (i) force tracking to quantify visuomotor precision, (ii) sequential finger tapping to measure motor sequence recall, (iii) single-finger tapping to assess temporal regularity, and (iv) multi-finger tapping to measure independence of finger movements. Diverse clinical and neuropsychological tests were also applied. A patient subgroup $(N=15)$ participated in a 14-week cognitive remediation protocol and was assessed before and after remediation. Compared to control subjects, patients with schizophrenia showed greater error in force tracking, poorer recall of tapping sequences, decreased tapping regularity, and reduced degree of finger individuation. A composite performance measure discriminated patients from controls with sensitivity $=0.79$ and specificity $=0.9$. Aside from force-tracking error, no other dexterity components correlated with antipsychotic medication. In patients, some dexterity components correlated with neurological soft signs, Positive and Negative Syndrome Scale (PANSS), or neuropsychological scores. This suggests differential cognitive contributions to these components. Cognitive remediation lead to significant improvement in PANSS, tracking error, and sequence recall (without change in medication). These findings show that multiple aspects of sensorimotor control contribute to impaired manual dexterity in schizophrenia. Only visuomotor precision was related to antipsychotic medication. Good diagnostic accuracy and responsiveness to treatment suggest that manual dexterity may represent a useful clinical marker in schizophrenia.

Keywords: schizophrenia, sensorimotor integration, manual dexterity, clinical marker, force control, independent finger movements

\section{INTRODUCTION}

Although cognitive impairments predominate in schizophrenia $(1,2)$, sensorimotor abnormalities have also been noted since its very first description (3) and later on $(1,4-7)$. There is, however, no consensus on the relevance of these symptoms. More specifically, the following issues would need to be clarified: (i) can these symptoms be attributed to (antipsychotic) medication? (ii) do they reflect a 
primary genuine deficit of the underlying pathophysiology? and (iii) if they are genuine, could quantitative measurement of these dysfunctions serve as useful clinical markers of schizophrenia?

Extrapyramidal symptoms $(8,9)$ and other (upper limb) motor deficits $(10,11)$ have been attributed to antipsychotic pharmacotherapy, but this is being questioned and increasingly considered not to be the main cause of sensorimotor abnormalities in schizophrenia $(7,12,13)$. Furthermore, sensorimotor control, rather than being impaired per se, has been viewed as being affected by abnormal cognitive function, such as deficient action planning (14-16).

However, evidence for genuine sensorimotor deficits in schizophrenia has been provided by investigating drug-naïve or differentially medicated subjects. Such deficits have been seen in psychomotor signs $(17,18)$, neurological soft signs (NSS) (19-22), postural control (23), micro-movements (24), eye movements (25-27), and upper limb control (28-31).

If sensorimotor impairments represent a primary deficit or covary with disease state, then measuring the degree of impairment could be clinically useful $(32,33)$, serve as a marker for vulnerability [e.g., Ref. $(34,35)]$ or describe neurodevelopmental abnormalities in schizophrenia $(20,36)$. However, validation of deficient dexterity as a clinical marker of schizophrenia (including assessment of sensitivity, specificity, and responsiveness) is lacking.

Here, we investigated manual dexterity in patients with schizophrenia, with the aim of probing its potential as a clinical marker. A high degree of manual dexterity (a hallmark of human upper limb use) requires efficient sensorimotor integration. Although different aspects of hand-use have been explored in schizophrenia, and often found to be deficient $(30,32,37-39)$, quantifiable (rather than qualitative) measures of dexterity have rarely been studied.

We used the Finger Force Manipulandum (FFM) in visuomotor tasks (40) to quantify four manual dexterity components: precision of force control, motor sequence recall, timing during finger tapping, and independence of finger movements. We predicted that all of these components of dexterity would be deficient in schizophrenia patients compared to a healthy control group. Moreover, we hypothesized that some of these components would correlate with clinical outcome scores (such as NSS), but that each component would show correlations with specific clinical and neuropsychological scores. For example, we predicted that sensorimotor integration measured with NSS would correlate more closely to precision of force control than to motor sequence recall. Conversely, given that schizophrenia is associated with a core deficit in working memory (41), we also predicted that motor sequence recall would correlate best with disease status according to the Positive and Negative Syndrome Scale (PANSS). We investigated whether the degree of dexterity discriminated patients from controls, whether individual profiles of dexterous impairment could be extracted and, furthermore, how dexterity related to clinical and neuropsychological outcome, to antipsychotic medication as well as to responsiveness to treatment (cognitive remediation).

\section{MATERIALS AND METHODS}

\section{Participants}

Thirty-five patients, 18-45 years of age, who met DSM-IV TR criteria (42) for schizophrenia were recruited at the
Resource Center for Cognitive Remediation and Psychosocial Rehabilitation (C3RP), Sainte-Anne Hospital, Paris. Patients were clinically stabilized and under psychotropic medication for at least 1 month. Exclusion criteria: substance abuse/dependence, neurological disorders, participation in other cognitive remediation programs, resistance to neuroleptic treatment, electroconvulsive therapy in the previous 6 months, piano playing for a number of years.

Patients passed clinical and neuropsychological assessments, and comprehensive testing of manual dexterity. Twenty healthy age-matched subjects served as control group for the dexterity assessment. Table 1 lists clinical and demographic information. The study, approved by the local ethics committee (study no. 2011-A00454-37, Comité de Protection des Personnes, Ile de France 3), complied with the Declaration of Helsinki. Subjects provided written informed consent.

\section{Remediation Protocol}

Cognitive remediation therapy (43-45), to alleviate dysexecutive impairments was completed by 15 patients. It lasted 14 weeks (40 sessions of $60 \mathrm{~min}$ each: 2 sessions/week in the C3RP, 12 sessions at home) and comprised exercises on executive functions including attention, cognitive flexibility, planning, and memory.

\section{Clinical and Neuropsychological Assessment}

Clinical evaluation (Table 1) comprised PANSS (46), NSS (22), and the Simpson-Angus Scale for rating abnormal movements (47).

Executive Function (Table 2) was assessed by selective attention [D2 test (48)], working memory [digit and spatial span of

TABLE 1 | Demographic and clinical characteristics of patients with schizophrenia and of control subjects.

\begin{tabular}{|c|c|c|}
\hline & $\begin{array}{l}\text { Patients } \\
(N=35)\end{array}$ & $\begin{array}{c}\text { Control } \\
\text { subjects } \\
(N=20)\end{array}$ \\
\hline & Mean \pm SD & Mean \pm SD \\
\hline \multicolumn{3}{|l|}{ Demographic characteristics } \\
\hline Age (years) & $31.2 \pm 10.3$ & $31.7 \pm 9.6$ \\
\hline Gender (male:female) & $24: 11$ & $13: 7$ \\
\hline Education (years) & $13.4 \pm 2.5$ & $16.9 \pm 1.8$ \\
\hline $\begin{array}{l}\text { Moberg pick-up test (functional } \\
\text { dexterity measure) }\end{array}$ & $16.8 \pm 7.6 \mathrm{~s}$ & $12.0 \pm 2.2 \mathrm{~s}$ \\
\hline \multicolumn{3}{|l|}{ Clinical characteristics } \\
\hline Age at first episode (years) & $21.2 \pm 6.4$ & \\
\hline Disease duration (years) & $12.1 \pm 9.1$ & \\
\hline Age of first antipsychotic treatment (years) & $21.4 \pm 5.3$ & \\
\hline Age of first hospitalization (years) & $23.6 \pm 6.8$ & \\
\hline Number of hospitalizations & $3.0 \pm 2.5$ & \\
\hline Simpson-Angus Extrapyramidal scale & $1.05 \pm 2.06$ & \\
\hline \multicolumn{3}{|l|}{ Antipsychotic treatment } \\
\hline Chlorpromazine equivalent (CPZe, mg/day) & $431 \pm 340$ & \\
\hline Other pharmacological treatments & $\%$ of Patients & \\
\hline Antidepressant & 34 & \\
\hline Anxiolytic & 26 & \\
\hline Anticholinergic & 11 & \\
\hline Hypnotic/sedative & 9 & \\
\hline Thymoregulator & 6 & \\
\hline
\end{tabular}


TABLE 2 | Patient group ( $N=35)$ : clinical and neuropsychological scores.

\begin{tabular}{|c|c|c|c|}
\hline \multirow[t]{2}{*}{ Clinical score } & \multirow{2}{*}{$\begin{array}{c}\text { Patients } \\
(N=35) \\
\text { Mean } \pm \text { SD }\end{array}$} & \multirow{2}{*}{$\begin{array}{c}\text { Pre-remediation } \\
\qquad\left(N=15^{i}\right) \\
\text { Mean } \pm \text { SD }\end{array}$} & \multirow{2}{*}{$\begin{array}{c}\text { Post-remediation } \\
\qquad\left(N=15^{i}\right)\end{array}$} \\
\hline & & & \\
\hline \multicolumn{4}{|l|}{ PANSS $^{a}$} \\
\hline Total score & $65.5 \pm 14.6$ & $68.3 \pm 10.3$ & $55.3 \pm 10.1^{\star \star}$ \\
\hline Positive symptoms & $11.5 \pm 3.5$ & $11.4 \pm 3.4$ & $10.9 \pm 3.5$ \\
\hline Negative symptoms & $18.25 \pm 5.2$ & $18.9 \pm 4.7$ & $15.7 \pm 4.7^{\star \star}$ \\
\hline $\begin{array}{l}\text { Disorganization } \\
\text { symptoms }\end{array}$ & $8.6 \pm 2.1$ & $10.2 \pm 2.3$ & $7.7 \pm 1.8^{\star \star}$ \\
\hline General symptoms & $35.8 \pm 10.3$ & $38.0 \pm 8.8$ & $28.8 \pm 6.9^{\star \star}$ \\
\hline \multicolumn{4}{|l|}{$\mathbf{N S S}^{b}$} \\
\hline Total score & $13.37 \pm 8.49$ & $9.0 \pm 4.7$ & $6.4 \pm 2.8^{\star}$ \\
\hline $\begin{array}{l}\text { Sensory integration } \\
\text { sub-score }\end{array}$ & $1.20 \pm 1.54$ & $1.4 \pm 1.6$ & $0.9 \pm 1.4$ \\
\hline $\begin{array}{l}\text { Motor coordination } \\
\text { sub-score }\end{array}$ & $2.16 \pm 2.03$ & $2.8 \pm 2.3$ & $1.9 \pm 2.1$ \\
\hline $\begin{array}{l}\text { Motor integration } \\
\text { sub-score }\end{array}$ & $0.31 \pm 0.62$ & $0.7 \pm 1.0$ & $0.4 \pm 0.5$ \\
\hline \multicolumn{4}{|c|}{ Neuropsychological test } \\
\hline \multicolumn{4}{|l|}{ WCST $^{c}$} \\
\hline $\begin{array}{l}\text { Total number of } \\
\text { categories }\end{array}$ & $4.85 \pm 2.02$ & $5.0 \pm 1.6$ & $5.4 \pm 1.3$ \\
\hline \multicolumn{4}{|l|}{ D2 ${ }^{\mathrm{d}}$} \\
\hline GZ & $397.81 \pm 106.21$ & $396.1 \pm 135.6$ & $457.9 \pm 108.9^{\star \star}$ \\
\hline$F \%$ & $3.7 \pm 4.35$ & $2.4 \pm 1.9$ & $2.7 \pm 2.5$ \\
\hline $\mathrm{KL}$ & $163.22 \pm 31.90$ & $166.5 \pm 33.4$ & $191.9 \pm 51.8^{\star \star}$ \\
\hline GZ-F & $390.77 \pm 81.27$ & $407.5 \pm 86.5$ & $450.3 \pm 106.8^{\star \star}$ \\
\hline \multicolumn{4}{|l|}{ WAIS-III } \\
\hline Digit span total & $8.33 \pm 2.71$ & $8.4 \pm 2.9$ & $9.1 \pm 2.1$ \\
\hline Spatial span total & $8.69 \pm 2.71$ & $8.2 \pm 2.6$ & $9.1 \pm 2.9$ \\
\hline Digit symbol-copy & $104.22 \pm 50.98$ & $106.1 \pm 36.2$ & $95.9 \pm 40.4$ \\
\hline \multicolumn{4}{|l|}{ BADS $^{f}$} \\
\hline $\begin{array}{l}\text { Zoo map test v1 } \\
\text { planific. Time }\end{array}$ & $157.74 \pm 163.74$ & $141.2 \pm 102.1$ & $172.9 \pm 243.0$ \\
\hline $\begin{array}{l}\text { Zoo map test v1 } \\
\text { total score }\end{array}$ & $4.13 \pm 3.50$ & $4.6 \pm 3.4$ & $5.5 \pm 3.6$ \\
\hline \multicolumn{4}{|l|}{ D-KEFS Tower test ${ }^{g}$} \\
\hline $\begin{array}{l}\text { Ratio time/disk } \\
\text { moves }\end{array}$ & $4.41 \pm 3.64$ & $3.2 \pm 0.8$ & $3.2 \pm 1.3$ \\
\hline $\begin{array}{l}\text { Ratio number of } \\
\text { moves/number of } \\
\text { minimal moves }\end{array}$ & $1.73 \pm 0.63$ & $1.6 \pm 0.4$ & $2.3 \pm 2.4$ \\
\hline \multicolumn{4}{|l|}{ Stroop ${ }^{h}$} \\
\hline $\begin{array}{l}\text { Ratio interference/ } \\
\text { denominator }\end{array}$ & $55.13 \pm 27.69$ & $61.5 \pm 26.6$ & $39.6 \pm 10.8^{\star}$ \\
\hline $\begin{array}{l}\text { Scores before and after } \\
{ }^{a} P A N S S \text { : Positive and I } \\
{ }^{b} N S S \text { : neurological sof } \\
\text { coordination, motor int } \\
{ }^{c} \text { WCST: Wisconsin Car } \\
{ }^{d} D 2: \text { The D2 Test of Att } \\
\text { eWAIS-III: Wechsler ad } \\
{ }^{t} B A D S \text { : behavioral Ass } \\
{ }^{9} D-K E F S \text { Tower Test: } \\
{ }^{h} \text { Stroop: The Stroop N } \\
{ }^{'} \text { Not all } 15 \text { patients con } \\
N=14 \text { for WCST, D2, } \\
N=13 \text { for BADS, D-K } \\
N=11 \text { for NSS. } \\
N=10 \text { for Stroop. } \\
{ }^{*} \text { Significant differences } \\
\text { Wilcoxon signed-rank }\end{array}$ & $\begin{array}{l}\text { r cognitive remediation } \\
\text { Negative Syndrome S } \\
\text { t signs (22): three NS } \\
\text { tegration, sensory inte } \\
\text { d-Sorting Test (51). } \\
\text { tention (48). } \\
\text { ult intelligence scale, } \\
\text { essment of Dysexecu } \\
\text { Delis-Kaplan Executive } \\
\text { europsychological Sc } \\
\text { npleted all listed tests } \\
\text { WAIS-III. } \\
\text { EFS. }\end{array}$ & $\begin{array}{l}\text { third ed (49). } \\
\text { tive Syndrome (52). } \\
\text { Function System }(53 \text {, } \\
\text { reening }(54,55) \text {. } \\
\text { pre- and post-remedi }\end{array}$ & up of patients $(N=15)$. \\
\hline
\end{tabular}

Wechsler Adult Intelligence Scale-III, WAIS-III (49)], word processing speed (digit symbol-copy of WAIS-III), cognitive flexibility [Wisconsin Card-Sorting Test (WCST) $(50,51)]$, action planning [zoo map test (52)], problem solving [D-KEFS Tower Test (53)], and inhibition [Stroop $(54,55)]$. The above neuropsychological tests have been shown to be reliable and valid in schizophrenia (i.e., with test-retest correlation $R>0.7$ or Cronbach's alpha $>0.7$ ): selective attention, D2 test (56); WAISIII (57); WCST (58); action planning, zoo map test (59); problem solving, D-KEFS Tower Test (60); Stroop (58).

\section{Manual Dexterity Components}

Finger movements were measured with the FFM, ${ }^{1}$ as previously described (40). Individual forces (of the index, middle, ring, and little finger) were sampled to a CED1401 (10 kHz sampling rate/ digit) under Spike2v6, ${ }^{2}$ which provided real-time visual display of digit forces, target instructions or target forces. The Moberg pick-up test (61) gave a complementary functional measure of dexterity.

\section{FFM Tasks}

(i) Finger force tracking (Figure 1A) was used to measure the ability to precisely control fingertip forces. By varying the force on the piston with the finger, the subject controlled a cursor on a computer screen and was instructed to follow the target force as closely as possible. Each of the 48 trials (eight blocks of six trials, four blocks with $1 \mathrm{~N}$, four with $2 \mathrm{~N}$ target force) consisted of a ramp-hold-and-release trajectory, followed by a resting-phase.

(ii) Sequential finger tapping was used to assess the ability to learn and recall finger movement sequences. It consisted of a 5-tap finger sequence involving the four digits. The subject was instructed by sequential visual cues to press the indicated piston as soon as the target appeared. Each of three different sequences (A, B, C) was repeated 10 times with visual cues (learning trials), and then repeated five times (trials without cues) from memory and as quickly as possible (recall).

(iii) Single-finger tapping was used to test the performance of repetitive finger tapping at 1,2, and $3 \mathrm{~Hz}$. After an initial tapping period (15 taps, with auditory cues) the subject was instructed to continue tapping at the same rate for a similar period, without auditory cues.

(iv) Multi-finger tapping was used to quantify the independence of finger movements. Subjects were instructed to reproduce different finger tap configurations following a visual cue. The configurations varied trial-by-trial (pseudorandomized) and consisted of one-finger taps (separate tap of index, middle, ring, or little finger) and two-finger configurations (simultaneous index-middle, index-ring, index-little, middle-ring, middle-little, or ring-little finger taps).

\footnotetext{
${ }^{1}$ www.sensix.fr.
}

${ }^{2}$ www.ced.co.uk. 


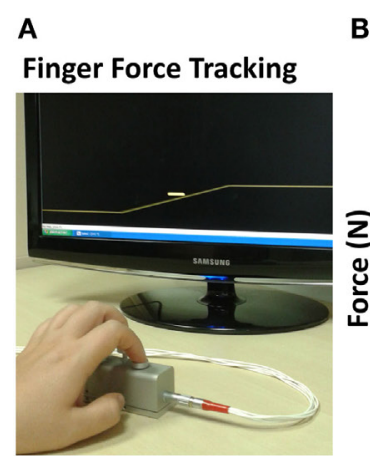

B

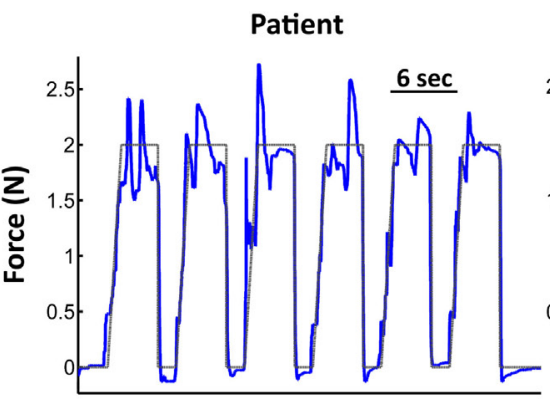

C

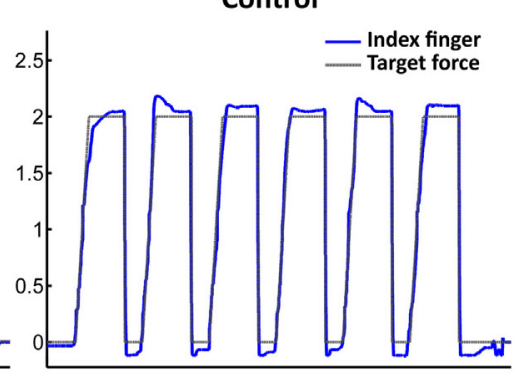

FIGURE 1 | Finger Force Manipulandum (FFM) setup and single subject force-tracking examples. (A) FFM with a screen providing visuomotor feedback during the finger force-tracking task. The yellow line on the screen represents the target force. The cursor (horizontal bar close to the ramp) represents the instantaneous force exerted by the index finger. The subject had to match the vertical cursor position to the right-left scrolling target force. Target force represents a ramp-hold-andrelease paradigm. Target forces of $1 \mathrm{~N}$ or $2 \mathrm{~N}$ hold-level correspond to a typical range employed in daily object manipulation. Subjects performed the task separately with the right index and the middle finger. (B,C) Single subject force-tracking examples of six successive trials at a target force (black trace) of $2 \mathrm{~N}$ with the index finger (blue trace). (B) For a patient. (C) For a control subject. Note greater tracking error in the patient.

\section{Data Analysis}

Task performance was analyzed using MatlabV7.5 (MathWorks Inc., Natick, MA, USA). Force signals were smoothed (5 ms sliding window) and down-sampled to $100 \mathrm{~Hz}$. The following task-specific performance measures were extracted trial-by-trial.

(i) Finger force tracking: (48 trials)

- Tracking error: root-mean-square error between applied and target force (separately extracted during ramp and hold).

- Force onset: force onset time relative to the target ramp onset.

- Release onset: onset time of force release relative to the end of the hold-phase.

- Release duration: time taken to abruptly reduce the applied force from 75 to $25 \%$ of the target force.

- Coefficient of variation (CV): SD/mean of force during $3 \mathrm{~s}$ of the hold-phase.

For the three tapping tasks, a peak detection algorithm identified timing (occurrence), amplitude $(>0.5 \mathrm{~N})$ and origin (finger) of each tap. Subsequently, all taps were categorized as either correct (detected tap $=$ required target tap) or incorrect (detected tap $\neq$ target tap). Incorrect trials consisted of "overflow taps" (presence of unwanted taps in non-target fingers while correctly tapping with the target finger) and "error taps" (presence of task-irrelevant taps in absence of a target finger tap). Subsequently, the following task-specific performance variables were calculated:

(ii) Sequential finger tapping: (45 trials). Two measures were computed for each 5-tap sequence:

- Number of correct taps among the required 5-tap sequence (unwanted extra-finger-taps or incorrect taps were neglected).

- Trial duration: period between the first and last tap of the required error-free sequence.

Each measure was averaged over trials and conditions. A "sequence recall score" was computed expressing the average number of correct taps during recall. (iii) Single-finger tapping: target finger taps were distinguished from taps in non-target fingers and the following measures calculated:

- Tap interval: interval between two successive target finger taps.

- Tap delay: time delay between the auditory signal and the target finger tap.

- Number of overflow and error taps (see above)

(iv) Multi-finger tapping (64 trials):

- Each trial was classified as correct or incorrect (presence of overflow taps and/or absence of target taps) and \% correct taps was calculated (providing a measure of the degree of finger individuation).

- Dual-tap interval: delay between the taps of the two fingers during trials requiring simultaneous two-finger tap configurations.

Respective measures were averaged/summed across trials and conditions.

\section{Statistical Analysis}

Student's $t$-test and Mann-Whitney $U$-test were used to test for group differences in parametric and non-parametric single-level variables. FFM measures were analyzed using repeated measures ANOVAs (Table 3). To extract individual profiles of dexterity we first selected the most discriminant "key-FFM" score (Table 3) in each task from group comparisons and then calculated individual $z$-scores for each key-FFM score, based on the control group's performance: a $z$-score $>2$ ( $>$ mean $+2 \mathrm{SD}$, one-tailed) was considered out of normal range (i.e., a deficient score). A composite score (sum of the four key-FFM $z$-scores) was used for computing a receiver-operating curve to discriminate patients from control subjects based on the degree (or severity) to which dexterity was affected.

Spearman's rank order or Pearson's correlations were used to investigate relations between key-FFM performance measures and clinical or neuropsychological scores, and antipsychotic 
TABLE 3 | Key measures of manual dexterity: relevant task-performance variables examined by ANOVA in each of the four FFM tasks.

\begin{tabular}{|c|c|c|c|c|}
\hline \multirow[t]{2}{*}{ ANOVA } & \multicolumn{4}{|c|}{ Finger Force Manipulandum (FFM) task } \\
\hline & Force tracking & Single-finger tracking & Sequential finger tapping & Multi-finger tapping \\
\hline \multirow[t]{5}{*}{ Independent variables } & Tracking error & Tap interval variability & Sequence recall score & $\begin{array}{l}\text { Degree of finger } \\
\text { individuation }\end{array}$ \\
\hline & Timing & Tapping rate & Number of correct taps & Dual-tap interval \\
\hline & Release duration & Mean tap interval & Trial duration & \\
\hline & & Mean tap delay & & \\
\hline & & Number of NLF taps & & \\
\hline Between-group factor & GROUP (patients, controls) & GROUP (patients, controls) & GROUP (patients, controls) & GROUP (patients, controls) \\
\hline \multirow{3}{*}{$\begin{array}{l}\text { Within-group factors (task } \\
\text { conditions) }\end{array}$} & FINGER (index, middle) & FREQUENCY (1, 2, 3 Hz) & SEQUENCE (sequence A, B, C) & \\
\hline & FORCE (1 N, 2 N) & FINGER (index, middle, ring, little) & $\begin{array}{l}\text { PHASE (1st half learning, } 2 \text { nd half } \\
\text { learning, recall) }\end{array}$ & \\
\hline & PHASE (Ramp, Hold) & PHASE (with cue, without cue) & & \\
\hline
\end{tabular}

Independent variables examined by ANOVA are given for each FFM task. In bold: the key-FFM score (one for each task), which was the most discriminant variable for differentiating the performance between groups (patients vs. normal subjects). Within-group factors in CAPITALS, with their respective levels in parenthesis. Post hoc tests were performed using Fisher LSD Test and FDR correction for multiple comparisons was applied (62).

medication. Remediation effects on clinical/neuropsychological scores were tested with the Wilcoxon test. Statistical analysis was performed under Statistica $\left({ }^{3}\right.$ and level of significance set to $P<0.05$. In correlation tests, significance level was corrected for multiple comparisons according to Benjamini and Hochberg (62).

\section{RESULTS}

\section{Clinical and Neuropsychological Data}

Patient and control groups were similar in gender and age (Table 1). However, patients were significantly slower than control subjects in performing the pick-up test (Table 1, $T=2.74$, $P=0.008$ ), suggesting a qualitatively decreased level of dexterity. Full clinical details and neuropsychological scores are given in Table 2.

\section{Group Comparisons: Precision of Visuomotor Tracking}

Patients with schizophrenia showed altered finger force control during force tracking (Figures 1B,C). Patients had significantly higher tracking error compared to controls (SZ_patients: $0.20 \pm 0.06 \mathrm{~N}$; controls: $0.14 \pm 0.04 \mathrm{~N}$; GROUP effect: $F=14.9$, $P=0.0003$; Figure 2A) in all conditions (FORCES, PHASES). Force variability $(\mathrm{CV})$ was also significantly increased in patients (SZ_patients: $2.86 \pm 1.08$; controls: $2.02 \pm 0.56$; GROUP effect: $F=4.6, P=0.04)$. No significant differences were found in timing (force onset and release onset) or in release duration.

\section{Group Comparisons: Recall of Tapping Sequence}

Patients ( $N=33$; two patients were excluded due to data acquisition problems) showed a significantly decreased number

${ }^{3}$ http://www.statsoft.com/. of correct taps over the entire task compared to controls (SZ_patients: $4.04 \pm 0.63$; controls: $4.68 \pm 0.25$; GROUP effect: $F=18.9, P=0.00007)$. This difference was even greater during recall (SZ_patients: $3.73 \pm 1.00$; controls: $4.74 \pm 0.30$; GROUP ${ }^{*}$ PHASE effect: $F=6.47, P=0.002$; post hoc test P3: $P<0.000001$; Figure 2B). During task progression, patients and controls increased the number of correct taps (TRIALS effect: $F=12.7, P<0.000001$; Figure 3A). When splitting the task into three consecutive phases [first (P1) and second (P2) half of the learning phase, and the recall phase (P3)], patients started the task with a significantly reduced number of correct taps compared to controls (SZ_patients: $3.89 \pm 0.68$; controls: $4.47 \pm 0.48$; GROUP/PHASE effect: $F=6.47, P=0.002$; post hoc test $\mathrm{P} 1$ : $P=0.002$; Figure $3 \mathrm{~B}$ ). Both groups increased their number of correct taps during the second learning phase (SZ_patients: $4.48 \pm 0.56$; post hoc test $\mathrm{P} 1 / \mathrm{P} 2: P=0.000001$; controls: $4.84 \pm 0.20$; post hoc test $\mathrm{P} 1 / \mathrm{P} 2: P=0.013)$, and patients reached a similar success rate as controls (somewhat lower, but statistically non-significant, post hoc test P2: $P=0.06$ ). During recall, controls maintained the same number of correct taps (controls: $4.74 \pm 0.30$; post hoc test $\mathrm{P} 2 / \mathrm{P} 3: P=0.49$ ) while the performance of the patients decreased to levels seen in the initial (P1) learning phase (SZ_patients: $3.73 \pm 1.00$; post hoc test P2/P3: $P=0.000001)$. Both groups made the same kind of errors during the task and patients had a significantly longer trial duration during recall compared to controls (SZ_patients: $2,674 \pm 693 \mathrm{~ms}$; controls: $2,027 \pm 480 \mathrm{~ms}$; GROUP effect: $F=12.9, P=0.00001)$.

\section{Group Comparisons: Timing in Single-Finger Tapping}

In the single-finger-tapping task, the average tap frequency was similar in patients and in control subjects, close to the 1,2 , and $3 \mathrm{~Hz}$ target frequency, during the cued as well as during the noncued phase. However, patients showed a significantly increased tap interval variability compared to controls (SZ_patients: $94.5 \pm 50$ ms; controls: $60.1 \pm 17.2$ ms; GROUP effect: $F=8.8$, $P=0.004$; Figure 2C), and this difference was similar in all 

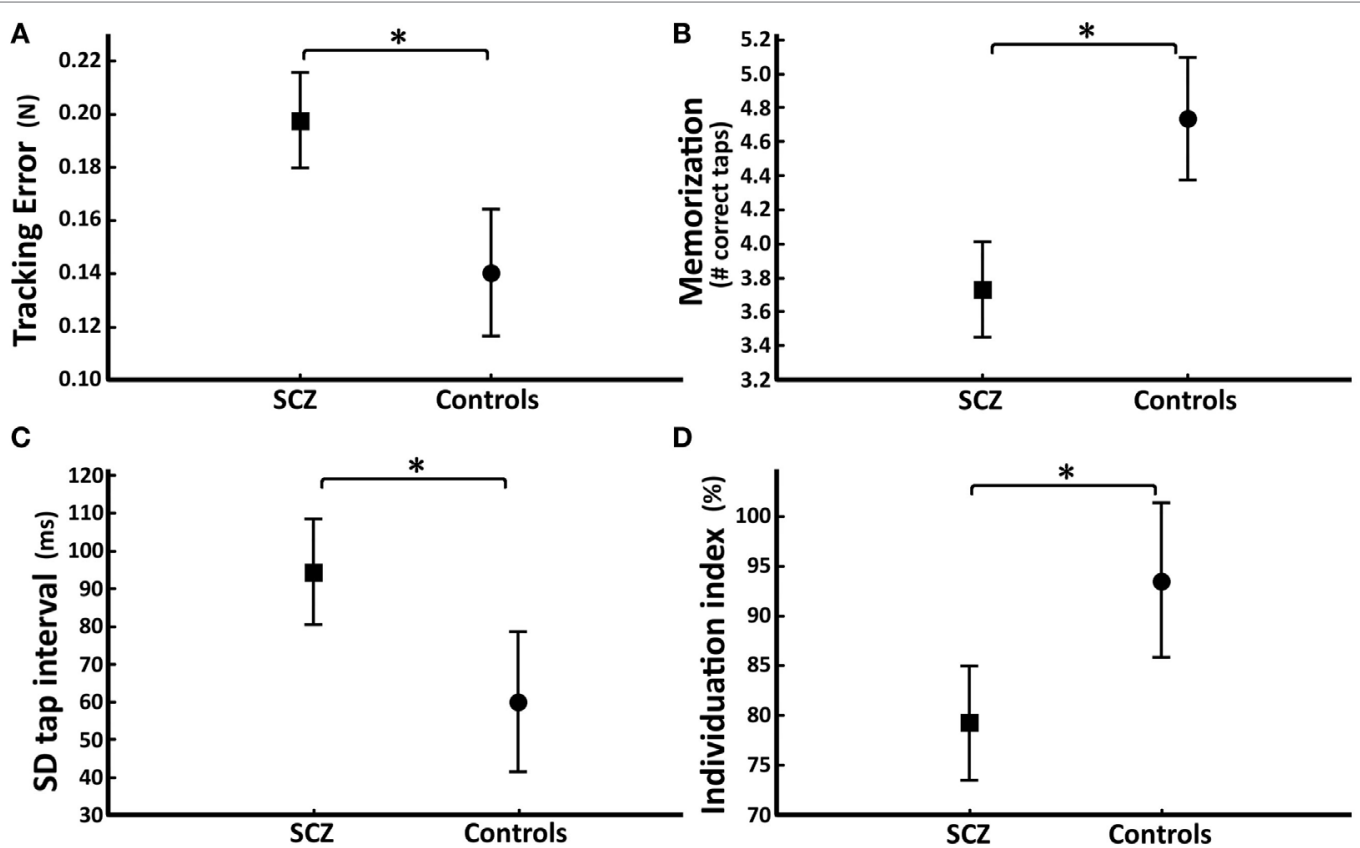

FIGURE 2 | Group differences in the four key-Finger Force Manipulandum (FFM) scores. Average score (and SD) for each task. Patients (SCZ, represented by squares) vs. control subjects (circles). (A) Tracking error (N) during the finger force-tracking task. (B) Number of correct taps per trial during recall of the sequential finger-tapping task. (C) Tap interval variability (ms) across all conditions of the single-finger-tapping task. (D) Degree of individuation across all fingers for every combination during the multi-finger-tapping task. Compared to control subjects, patients with schizophrenia showed a statistically significant difference $\left({ }^{\star} P<0.05\right)$ in all four key-FFM scores.
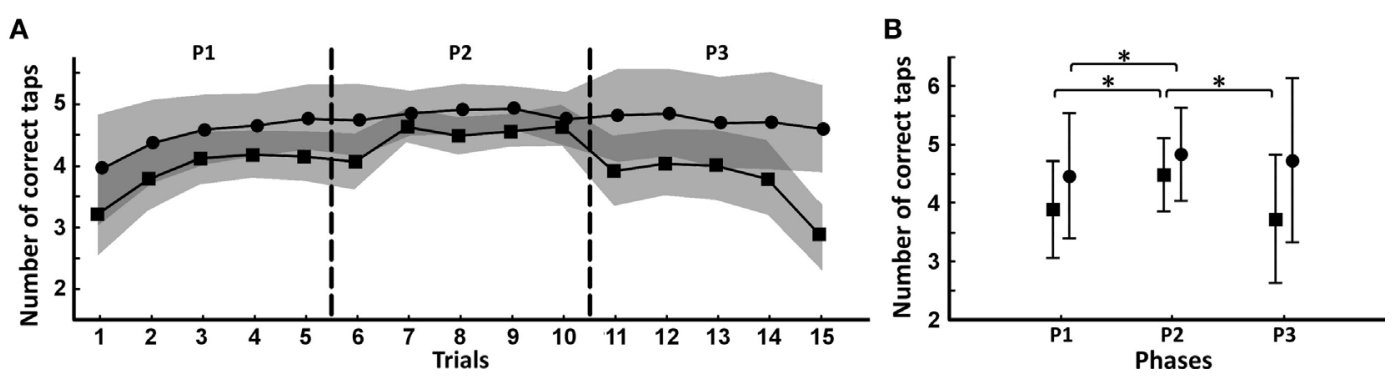

FIGURE 3 | Evolution of performance during the sequential finger-tapping task. (A) Mean number of correct taps per trial across the 15 trials for the patient group (squares) and for the control group (circles). Vertical stippled lines indicate the three successive phases of the task. The SE of each group is represented by a gray area around the mean values (dark gray: overlap). (B) Mean number of correct taps for each phase consisting of five trials (P1: first half of the learning phase, P2: second half of the learning phase, P3: recall phase) in patient group (squares) and control group (circles). Horizontal lines represent within-group comparisons between $\mathrm{P} 1 / \mathrm{P} 2 / \mathrm{P} 3$. * Significant difference $P<0.05$.

conditions (FINGER, FREQUENCY, PHASE). There was no group difference in other task measures (erroneous taps).

\section{Group Comparisons: Independence of Finger Movements}

In the multi-finger-tapping task, patients showed a significantly reduced degree of finger individuation compared to controls (SZ_patients: $79 \pm 20 \%$; controls: $94 \pm 6 \%$; GROUP effect: $F=9.0, P=0.004$; Figure 2D). This was the case in all fingers and for single- or multi-finger tap configurations. Patients also had significantly longer dual-tap intervals (SZ_patients:
$380 \pm 18 \mathrm{~ms}$; controls: $304 \pm 24 \mathrm{~ms}$; GROUP effect: $F=6.6$, $P=0.01)$.

\section{Heterogeneity of Dexterity Profiles}

Individual dexterity profiles are shown as radar plots of the four key-FFM measures (Figure 4). Four types of profiles were distinguished according to the number of affected $z$-scores in each patient. "Profile_0" ( $N=7$ patients) with all $z$-scores $<2$ (i.e., nonaffected), "profile_1" $(N=13)$ with one affected $z$-score $>2$, "profile_2" $(N=4)$ with two affected scores, and "profile_3" $(N=9)$ with three or four affected $z$-scores. Sequence recall was the most 
frequently affected component $(N=16)$, followed by degree of individuation, ramp error, and tap interval variability. Profile_0 showed homogeneous radar plots (Figure 4A) with all $z$-scores $<2$ (below pathology threshold). In profile_1 the majority of the patients had affected $z$-scores close to threshold $(3>z$-score $>2$; Figure 4B). In profile_2 and profile_3 (Figures 4C,D), most of the affected $z$-scores were $>3$ or $>4$, resulting in heterogeneous, large amplitude patterns. Qualitatively, patients with a large number $(>2)$ of affected scores also showed highly abnormal values $(z$-score $>3$; Figure 4$)$. Furthermore, dexterity profiles showed strong heterogeneity with only $15 \%$ of patients showing abnormal values in a common set of components.

\section{Low Covariance between Key-FFM Measures}

The heterogeneity among dexterity profiles suggested that each key-FFM component represents a specific element of control, independent from the other components. A quantitative estimate of their independence was obtained by pair-wise Pearson correlations: this showed that only one among the six pair-wise correlations was statistically significant, i.e., tap interval variability vs. degree of individuation $(r=0.54, P<0.05$, Dof $=32)$. This lack of systematic covariance between key-FFM scores indicates a large (but not perfect) independence among component measures.

\section{Sensitivity and Specificity of Key-FFM Measures}

The composite dexterity measure (sum of the four key-FFM scores) was analyzed using receiver-operating characteristics (ROC) to test for sensitivity and specificity (Figure 5). A $\log$ value of 1.2 , corresponding to a score $=3.3$, yielded best discrimination between patients and controls, with a positive predictive power $=0.93$ and a negative predictive power $=0.9$. In comparison, ROC analysis of each single key-FFM score provided lower discriminative power. Similarly, using the NSS total score as a means of discrimination (mean $=5 \pm 2$, threshold $=9$,
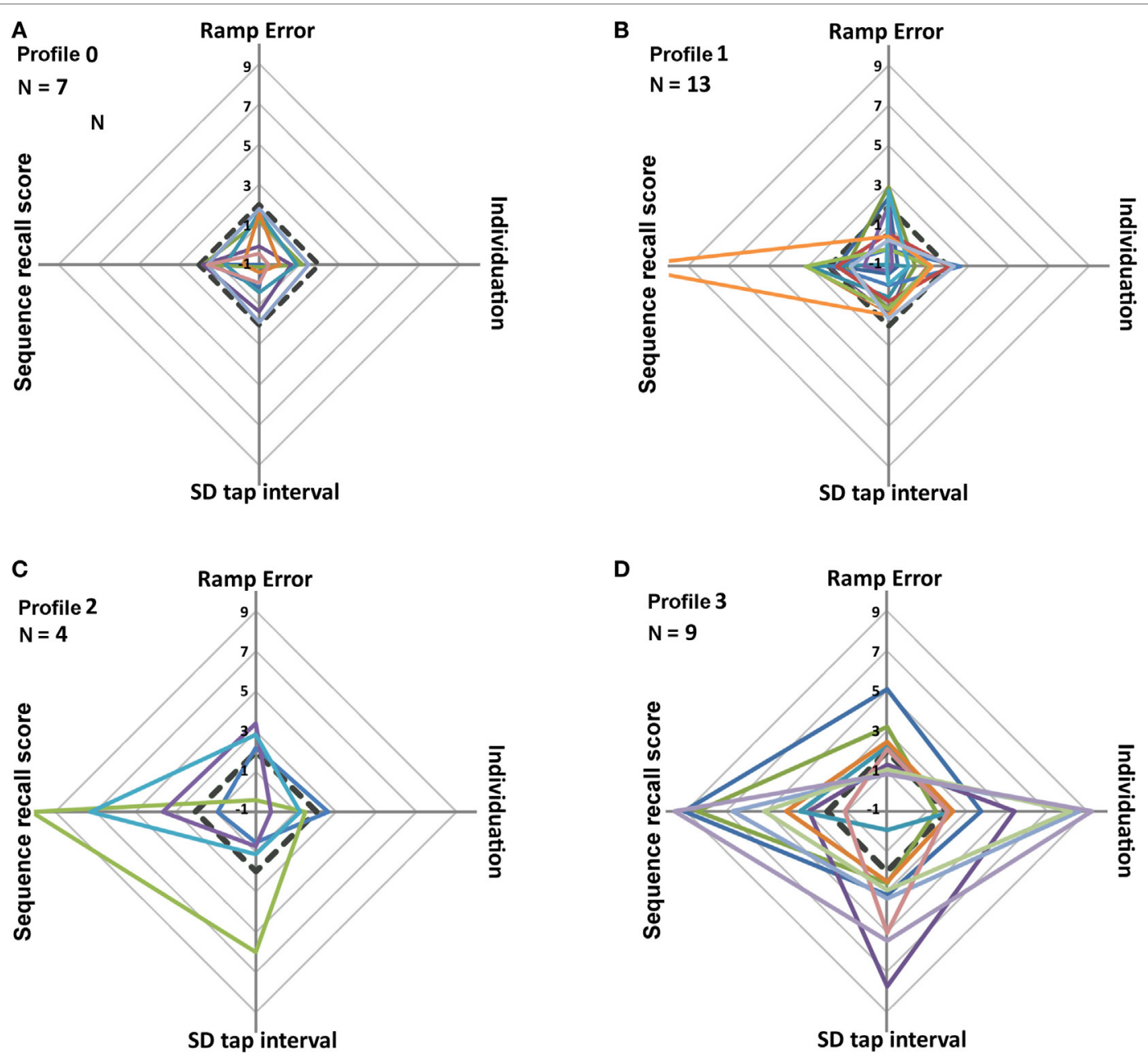

FIGURE 4 | Radar plots of the four key-Finger Force Manipulandum scores (ramp error in finger force tracking, degree of individuation in multi-finger tapping, tap interval variability in single-finger tapping, and sequence recall index in sequential finger tapping). Each measure represents a $z$-score relative to the mean and SD of the control group. The 33 patients were subdivided into four types of dexterity profiles (A-D) according to the number of affected $z$-scores per patient. (A) Profile_0 (all $z$-scores <2). (B) Profile_1 (one $z$-score $>2$ ). (C) Profile_2 (two $z$-scores $>2$ ). (D) Profile_3 (three or four $z$-scores $>2$ ). Black dotted lines represent the normality threshold $($ mean $+2 \mathrm{SD})$. Scores $>$ threshold are considered abnormal. 

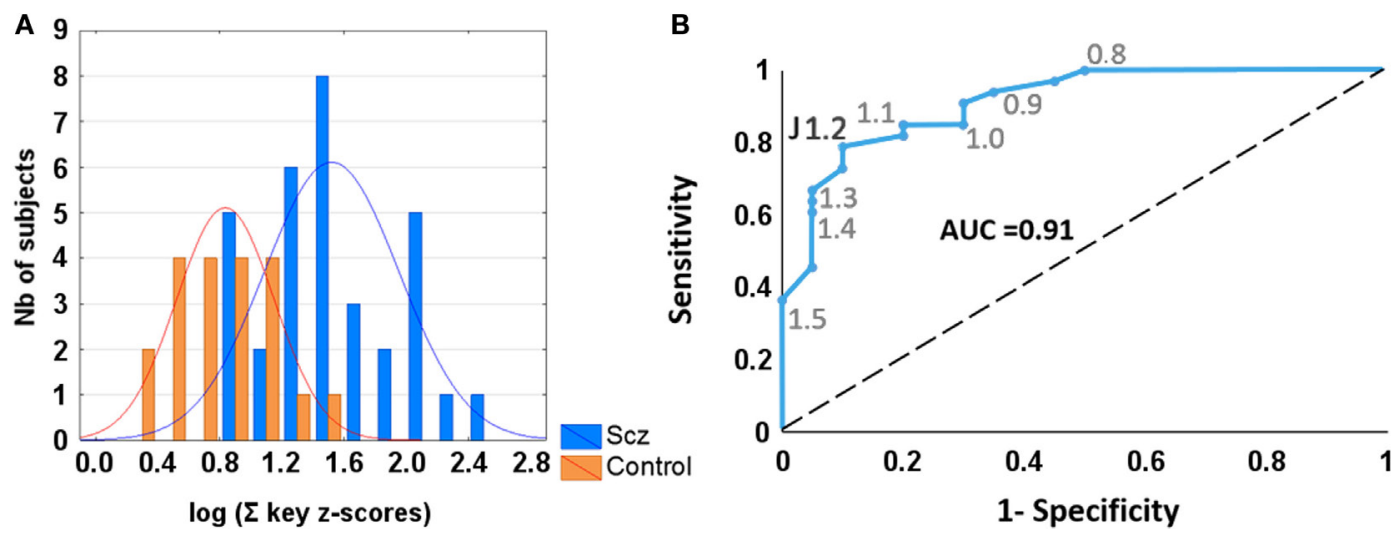

FIGURE 5 | (A) Histograms of log-transformed summed key-Finger Force Manipulandum scores in patients with schizophrenia (blue vertical bars) and control subjects (orange bars). (B) Receiver-operating characteristic curve showing sensitivity and specificity of various criterion levels. Youden's $\mathrm{J}$ statistic shows that the optimal value of 1.2 gives sensitivity $=0.79$ and specificity $=0.9$. Large area under curve (AUC $=0.91$ ) suggests positive diagnostic interest of summed dexterity score.
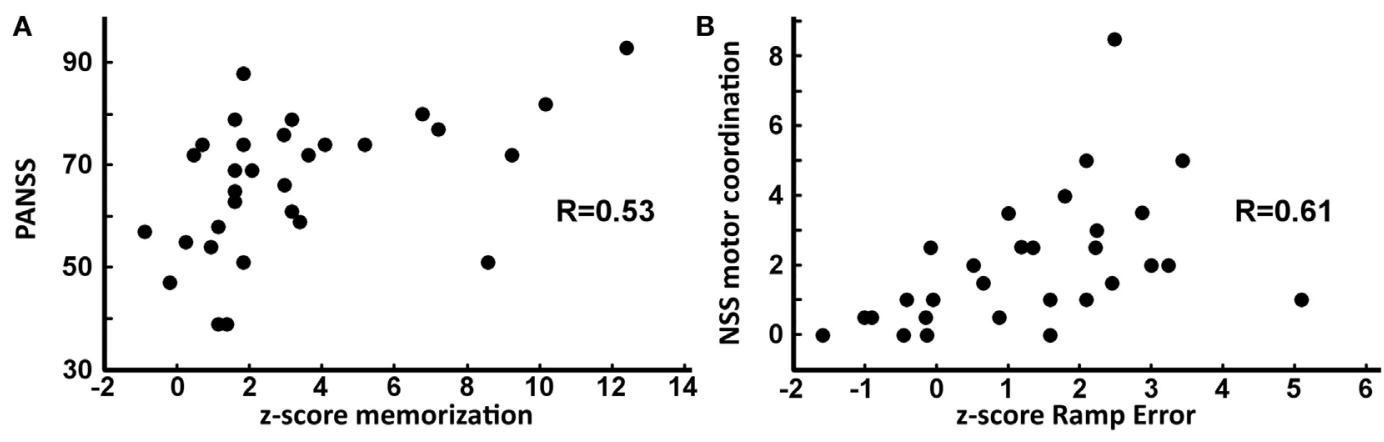

C

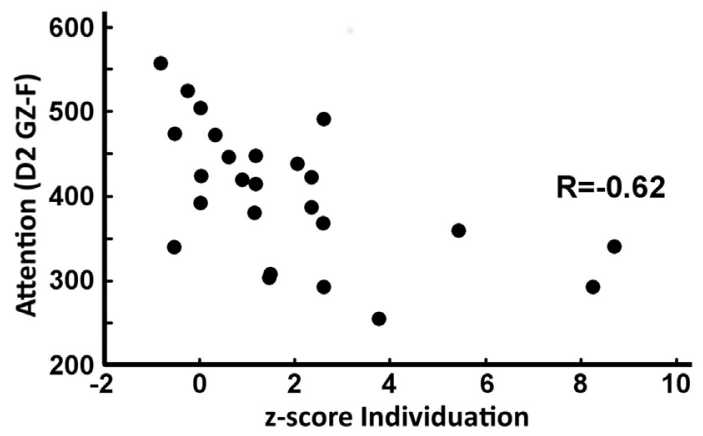

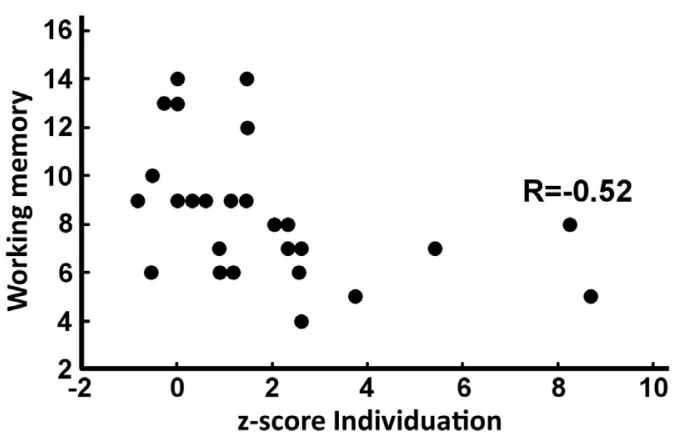

FIGURE 6 | Relation (Spearman correlations) between key-Finger Force Manipulandum z-scores and clinical or neuropsychological scores. (A) Positive correlation between sequence recall score and total Positive and Negative Syndrome Scale (PANSS) score $(R=0.53, P=0.0019)$. (B) Positive correlation between ramp error and motor coordination neurological soft sign (NSS) sub-score $(R=0.53, P=0.003)$. (C) Negative correlation between degree of individuation and GZ-F D2 attention sub-score $(R=-0.62, P=0.0009)$. (D) Negative correlation between degree of individuation and working memory score $(R=-0.52, P=0.005)$.

obtained from (22)) resulted in weaker positive predictive power (0.65).

\section{Relation between FFM Measures and Clinical Outcomes}

For patients with schizophrenia, correlations were computed between key-FFM scores and clinical (PANSS; NSS) and neuropsychological (D2, WAIS-III) outcomes. Briefly, FFM sequence recall scores correlated with PANSS total scores (Figure 6A; $r=0.53$ ) and with PANSS disorganization scores $(r=0.55, P<0.05$, Dof $=30)$. FFM tracking error correlated with NSS motor coordination (Figure 6B; $r=0.61$ ), with NSS sensory integration $(r=0.52)$ and with NSS motor integration $(r=0.53$, $P<0.05$, Dof $=28$ ). FFM tap interval variability did not show 
any correlations. FFM degree of individuation correlated with NSS sensory integration sub-score $(r=0.50, P<0.05$, Dof $=28)$, with different sub-scores of the D2 test of attention (Figure 6C; D2 GZ $(r=-0.61)$, D2 KL $(r=-0.63)$ and D2 GZ-F $(r=-0.62)$, $P<0.05$, Dof $=25)$, and with the WAIS-III working memory score (Figure 6D; $r=-0.52, P<0.05$, Dof $=26$ ). No relation was found between FFM measures and the scores of Stroop, D-KEFS Tower or BADS.

\section{Potential Influence of Medication}

The chlorpromazine equivalent (CPZe) correlated positively with the composite dexterity measure $(r=0.50 ; P=0.005$; Dof $=28)$, but not with single key-FFM scores, except for ramp error $(r=0.47, P<0.05$, Dof $=28)$.

Additional multiple regression analyses showed that correlations between each of the three key-FFM scores (degree of individuation, tap interval variability, and sequence recall) with clinical and neuropsychological outcomes (Table 3) remained significant even with CPZe as a covariate, indicating that antipsychotic medication could not completely explain these relations. Furthermore, two different key-FFM scores (tap interval variability and individuation) were more affected in patients with prescribed anxiolytic medication (in $26 \%$ of patients), but not with mood stabilizers, antidepressants, or anticholinergic medication.

\section{Change of Dexterity and of Clinical/ Neuropsychological Scores with Cognitive Remediation}

In the post-remediation condition, ANOVA showed a significantly decreased ramp error during force tracking (T1/T2 effect: $F=8.86, P=0.009$; Figure 7A), and also a significantly increased sequence recall score during sequential finger tapping (T1/T2 effect: $F=10.26, P=0.005$; Figure $7 B$ ). Remediation did not lead to significant changes in tap interval variability or degree of finger individuation.

Changes in clinical and neuropsychological scores following remediation are listed in Table 2. In particular, PANSS total score (Wilcoxon $Z=2.95, P=0.003$ ) and sub-scores (Negative: $Z=2.73, P=0.006$; General: $Z=2.73, P=0.006$; Disorganization: $Z=2.86, P=0.004)$ decreased significantly after remediation, except for the Positive subscale. The total NSS score also decreased significantly after remediation $(Z=2.04, P=0.04)$ but not the sub-scores. Among the neuropsychological scores, those related to attention (D2, Stroop) improved significantly.

\section{DISCUSSION}

Manual dexterity, quantified by four behavioral components extracted from four visuomotor tasks, was significantly affected in stabilized patients with schizophrenia. In the patient group, each component was significantly impaired compared to control subjects. This concerned (i) lower force-tracking accuracy, (ii) higher variability during repetitive finger tapping, (iii) more errors during memorized finger sequences, and (iv) lower degree of finger individuation. Patients showed individually different profiles of deficient manual dexterity. A composite performance measure discriminated patients with schizophrenia from control subjects with a sensitivity of $79 \%$ and a specificity of $90 \%$. Only tracking error and degree of individuation correlated with NSS scores, suggesting that together these four components capture new and complementary information on manual dexterity in schizophrenia.

\section{Affected Dexterity Components: Correlation to Clinical Status and Medication}

In terms of force tracking, which requires visuomotor matching and fine on-line adjustments of low finger forces, clear deficits were found in patients with schizophrenia: they produced about $40 \%$ more error than controls, similar to deficits found in controlling power grip forces (30) and consistent with less accurate control of steady grip (32) and finger flexion force (28). However, grasp function (evaluated by the ratio of grip/load force) was not or only marginally affected in schizophrenia $(37,63)$, and when
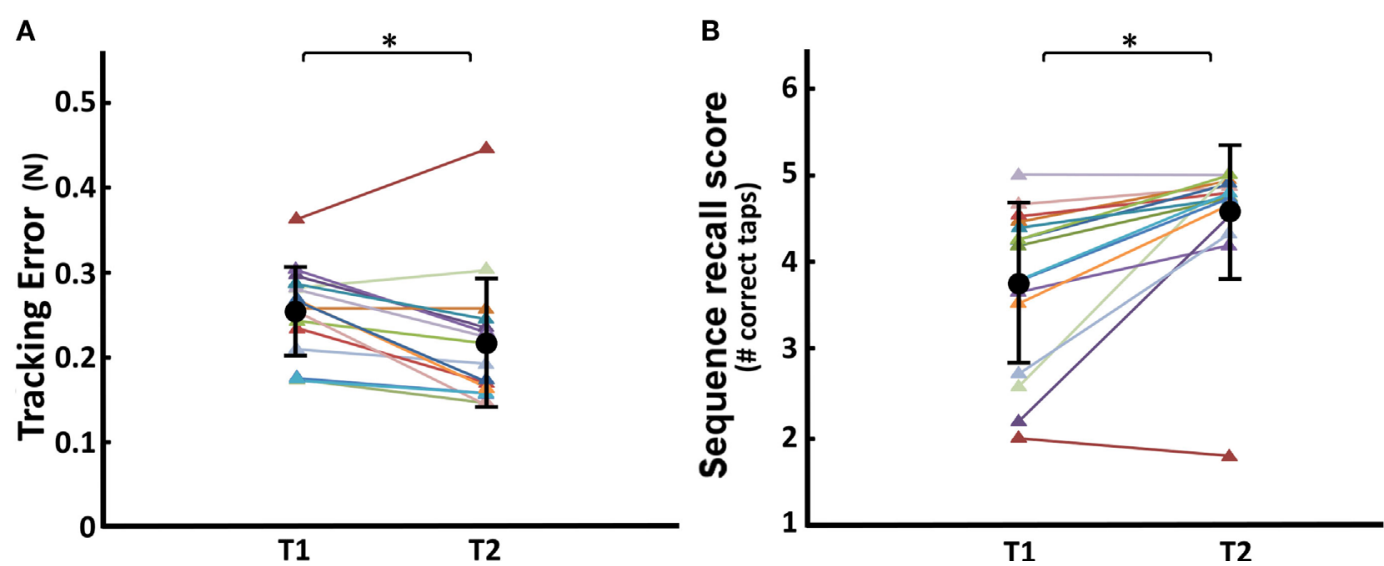

FIGURE 7 | Comparison of pre- and post-remediation performance in dexterous control. (A) Finger Force Manipulandum (FFM) tracking error. (B) FFM sequence recall score. T1, pre-remediation; T2, post-remediation. Group average \pm SD in black circle and bars, respectively. Colored triangles and lines represent individual scores $(N=15)$ across each condition. *Significant difference T1 vs. T2 at $P<0.05$. 
affected, it was considered a side effect of antipsychotic medication (10). There is thus clear evidence for a deficit in voluntary and visually controlled force modulation, but less so for force control during grasp. Visuomotor force tracking requires real-time sensorimotor mapping and integration, and the patients' precision in this task correlated positively with NSS sub-scores in motor coordination, motor integration and sensory integration. This validates that these NSS sub-scores reflect lack of precision (clumsiness) in tasks requiring sensorimotor integration. Interestingly, visuomotor precision (ramp error) was the only key-FFM score to correlate with antipsychotic medication (CPZe).

The sequential finger-tapping task required successive activation of fingers to produce movement sequences in the context of procedural learning: patients with schizophrenia performed significantly less well than controls, in particular during recall. Nonetheless, during learning patients reached a level similar to control subjects, suggesting that altered memory processing and not learning might be the cause of this deficit. These data agree with previous results on motor sequence learning involving finger-thumb opposition in schizophrenia (64). However, motor sequencing is more generally affected, as shown by studies on grip control (38), planned grasping (63), and other tasks (e.g., NSS (65)). Sequence recall correlated with the PANSS (global and disorganization sub-score). This (rather weak) association (in line with (66)) might not be surprising, since cognitive aspects contribute far more to PANSS scores than sensorimotor components or deficient dexterity (67). The lack of correlations between the FFM recall score and working memory scores (WAIS-III) might be related to differences between cognitive and procedural learning $(68,69)$.

The finger-tapping task required primarily temporal motor coordination. Deficits in finger-tapping tasks, such as reduced maximal tapping speed $[(18,68,70,71)$, but not in Ref. (72)], higher than required tapping frequency (73), and higher tapping variability $(5,73)$ have been previously shown. We found increased tapping variability, but not increased tapping frequency, whether cued or not (most likely due to our more constrained task conditions). Finger-tapping performance has been considered as a potential endophenotype, with a typical performance gradient that increased from patients, to unaffected relatives and finally to control subjects $(18,70,71)$. However, timing, as assessed with the FFM task, did not correlate to any of the clinical/neuropsychological tests or to antipsychotic medication.

The degree of finger individuation (assessed during multifinger tapping) was significantly lower in patients with schizophrenia. Although finger individuation is a key feature of manual dexterity (74), to our knowledge, this has not been previously quantified in schizophrenia. However, the Purdue Pegboard test, which requires some (non-quantifiable) degree of finger independence, has repeatedly been used and might be compared to our degree of finger individuation: schizophrenia patients showed lower Pegboard scores than controls $(31,39,72)$ and deficient scores were related to social functioning (38). In our case, degree of finger individuation correlated with sensory integration (NSS sub-score), with attention (D2 score), and with working memory (WAIS score). Tentatively, this may be interpreted as common cognitive operations involved in task-related finger individuation, requiring (i) visuomotor mapping (NSS) to determine the digits to be moved (and those not to), (ii) working memory (WAIS-III) to maintain this mapping, and (iii) focused attention (D2) since targets changed unpredictably. The lower scores in these basic cognitive operations may (in part) explain the resulting deficit in finger individuation, and are in line with neurocognitive deficits observed in schizophrenia $(1,75)$. This does not exclude that the motor command itself or its transmission via the corticospinal tract may be perturbed $(76,77)$.

\section{Limitations of the Study}

Our sample of stabilized patients may have masked even stronger deficits in dexterity, likely to be present in more severely affected (refractory or acute phase) patients with schizophrenia (78). A larger sample may also permit identification of subgroups of dexterity profiles and investigation of their relation to neuropsychological/clinical subtypes [e.g., Ref. (79)]. The absence of drug-naïve patients prevented us from providing direct evidence against an antipsychotic medication effect on the dexterity scores. There is, however, indirect evidence (see below) and evidence from other studies against this assumption (28-31). Similar limitations (plus a significant dropout rate) affected the remediation protocol. Some of these issues and others, such as the specificity of deficient dexterity components, their potential use as trait or state markers, or their occurrence in "high risk" populations, might be addressed in future studies.

\section{Can Antipsychotic Medication Explain Impaired Dexterity?}

A number of findings speak against antipsychotic medication as a main cause of deficient dexterity in schizophrenia. First, ramp error decreased after cognitive remediation, while antipsychotic medication $(\mathrm{CPZe})$ remained constant. Second, CPZe only correlated with ramp error but not with motor sequence recall, timing, or independence of finger movements. Third, the observed correlations between these three dexterity scores and clinical/neuropsychological scores (Table 3) were robust when adding CPZe as a covariate. This is consistent with previous studies on upper limb deficits vs. antipsychotic medication in schizophrenia (28-31).

\section{Individual Differences in Dexterity Profiles: Toward a Useful Clinical Marker?}

Our results provide quantitative evidence at the group level that dexterity is affected in schizophrenia, that four different components of dexterity can be distinguished, that each is significantly affected, and that these components are largely independent of each other. Whether the heterogeneous profiles at the individual level will cluster into subtypes and correlate with clinical phenotypes in schizophrenia [e.g., Ref. (79)] needs further investigation. Discrimination between patients and controls using ROC showed that affected manual dexterity provided a measure with a sensitivity of $79 \%$ and a specificity of $90 \%$. Thus dexterity, quantified with FFM, showed a better discrimination than total NSS score and showed similar predictive accuracy compared to gaze deficits $(80,81)$. Therefore, manual dexterity may well be considered a potential clinical marker in schizophrenia. 


\section{Responsiveness to Cognitive Remediation}

After cognitive remediation patients showed an improvement in main clinical and neuropsychological scores. Moreover, patients also improved significantly in two of the four main FFM scores, suggesting that these measures are sensitive enough to detect small variations in manual dexterity, only in part captured by NSS. Crucially, the remediation protocol did not include any FFM training, but used more general aspects of sensorimotor training. This suggests that tracking error and sequence recall, which varied as a function of remediation, may be more staterelated [similar to NSS (82)], whereas degree of individuation and tap variability, remediation invariant, may be considered potential trait markers.

In conclusion, our results are consistent with deficits in manual dexterity being a genuine phenotype of the underlying pathophysiology in schizophrenia. Our data suggest that quantitative assessment of these dysfunctions may serve as useful clinical markers in schizophrenia.

\section{ETHICS STATEMENT}

The study, approved by the local ethics committee (study no. 2011-A00454-37), complied with the Declaration of Helsinki. Subjects provided written informed consent.

\section{REFERENCES}

1. Mesholam-Gately RI, Giuliano AJ, Goff KP, Faraone SV, Seidman LJ. Neurocognition in first-episode schizophrenia: a meta-analytic review. Neuropsychology (2009) 23:315-36. doi:10.1037/a0014708

2. Kahn RS, Keefe RSE. Schizophrenia is a cognitive illness: time for a change in focus. JAMA Psychiatry (2013) 70:1107-12. doi:10.1001/jamapsychiatry. 2013.155

3. Bleuler E. Dementia Praecox oder Gruppe der Schizophrenien. Leipzig: International Universities Press (1950).

4. Morrens M, Docx L, Walther S. Beyond boundaries: in search of an integrative view on motor symptoms in schizophrenia. Front Psychiatry (2014) 5:145. doi:10.3389/fpsyt.2014.00145

5. Manschreck TC, Maher BA, Waller NG, Ames D, Latham CA. Deficient motor synchrony in schizophrenic disorders: clinical correlates. Biol Psychiatry (1985) 20:990-1002. doi:10.1016/0006-3223(85)90197-0

6. Wolff AL, O'Driscoll GA. Motor deficits and schizophrenia: the evidence from neuroleptic-naïve patients and populations at risk. JPsychiatry Neurosci (1999) 24:304-14.

7. Putzhammer A, Klein HE. Quantitative analysis of motor disturbances in schizophrenic patients. Dialogues Clin Neurosci (2006) 8:123-30.

8. Peluso MJ, Lewis SW, Barnes TRE, Jones PB. Extrapyramidal motor side-effects of first- and second-generation antipsychotic drugs. $\mathrm{Br}$ J Psychiatry (2012) 200:387-92. doi:10.1192/bjp.bp.111.101485

9. Lerner V, Miodownik C. Motor symptoms of schizophrenia: is tardive dyskinesia a symptom or side effect? A modern treatment. Curr Psychiatry Rep (2011) 13:295-304. doi:10.1007/s11920-011-0202-6

10. Nowak DA, Connemann BJ, Alan M, Spitzer M. Sensorimotor dysfunction of grasping in schizophrenia: a side effect of antipsychotic treatment? J Neurol Neurosurg Psychiatr (2006) 77:650-7. doi:10.1136/jnnp.2005.084749

11. Caligiuri MP, Teulings H-L, Dean CE, Niculescu AB, Lohr JB. Handwriting movement kinematics for quantifying extrapyramidal side effects in patients treated with atypical antipsychotics. Psychiatry Res (2010) 177:77-83. doi:10.1016/j.psychres.2009.07.005

12. Peralta V, Campos MS, De Jalón EG, Cuesta MJ. Motor behavior abnormalities in drug-naïve patients with schizophrenia spectrum disorders. Mov Disord (2010) 25:1068-76. doi:10.1002/mds.23050

\section{AUTHOR CONTRIBUTIONS}

MT collected data and performed statistical analysis and drafted first version of manuscript. LC performed some data analysis and contributed to the Section "Material and Methods" part of this manuscript. LB-H and MC collected data on neuropsychological performance of the patients and contributed to the methods and discussion parts about these measures. IA was responsible for study design, recruitment and the clinical assessments, and editing of full manuscript. PL, M-OK, and MM contributed to the conception of this protocol, interpreted results, and edited the manuscript.

\section{ACKNOWLEDGMENTS}

The authors would like to thank Brigitte Malangin, Bérangère Rigaut, Charlotte Danset-Alexandre, and Kevin Marseau of the Centre Ressource de Remédiation Cognitive et Réhabilitation Psychosociale (C3RP), as well as the staff of the Service HospitaloUniversitaire (SHU) Sainte-Anne, Paris, France for assistance.

\section{FUNDING}

This study was in part supported by the Institut national de la santé et de la recherche médicale (INSERM, France).

13. Pappa S, Dazzan P. Spontaneous movement disorders in antipsychotic-naive patients with first-episode psychoses: a systematic review. Psychol Med (2009) 39:1065-76. doi:10.1017/S0033291708004716

14. Giersch A, Wilquin H, Capa RL, Delevoye-Turrell YN. Combined visual and motor disorganization in patients with schizophrenia. Front Psychol (2013) 4:620. doi:10.3389/fpsyg.2013.00620

15. Grootens KP, Vermeeren L, Verkes RJ, Buitelaar JK, Sabbe BGC, van Veelen N, et al. Psychomotor planning is deficient in recent-onset schizophrenia. Schizophr Res (2009) 107:294-302. doi:10.1016/j.schres.2008.09.032

16. Bender J, Reuter B, Möllers D, Kaufmann C, Gallinat J, Kathmann N. Neural correlates of impaired volitional action control in schizophrenia patients. Psychophysiology (2013) 50:872-84. doi:10.1111/psyp.12060

17. Docx L, Sabbe B, Fransen E, Bervoets C, Hulstijn W, Van Den Bossche MJA, et al. Longitudinal evaluation of the psychomotor syndrome in schizophrenia. J Neuropsychiatry Clin Neurosci (2014) 26:359-68. doi:10.1176/appi. neuropsych.13020027

18. Flyckt L, Sydow O, Bjerkenstedt L, Edman G, Rydin E, Wiesel FA. Neurological signs and psychomotor performance in patients with schizophrenia, their relatives and healthy controls. Psychiatry Res (1999) 86:113-29. doi:10.1016/ S0165-1781(99)00027-X

19. Jahn T, Hubmann W, Karr M, Mohr F, Schlenker R, Heidenreich T, et al. Motoric neurological soft signs and psychopathological symptoms in schizophrenic psychoses. Psychiatry Res (2006) 142:191-9. doi:10.1016/j. psychres.2002.12.003

20. Chan RCK, Xu T, Heinrichs RW, Yu Y, Wang Y. Neurological soft signs in schizophrenia: a meta-analysis. Schizophr Bull (2010) 36:1089-104. doi:10.1093/schbul/sbp011

21. Gay O, Plaze M, Oppenheim C, Mouchet-Mages S, Gaillard R, Olié J-P, et al. Cortex morphology in first-episode psychosis patients with neurological soft signs. Schizophr Bull (2013) 39:820-9. doi:10.1093/schbul/sbs083

22. Krebs MO, Gut-Fayand A, Bourdel M, Dischamp J, Olié J. Validation and factorial structure of a standardized neurological examination assessing neurological soft signs in schizophrenia. Schizophr Res (2000) 45:245-60. doi:10.1016/ S0920-9964(99)00206-6

23. Kent JS, Hong SL, Bolbecker AR, Klaunig MJ, Forsyth JK, O'Donnell BF, et al. Motor deficits in schizophrenia quantified by nonlinear analysis of postural sway. PLoS One (2012) 7:e41808. doi:10.1371/journal.pone.0041808 
24. Nguyen J, Majmudar U, Papathomas TV, Silverstein SM, Torres EB. Schizophrenia: the micro-movements perspective. Neuropsychologia (2016) 85:310-26. doi:10.1016/j.neuropsychologia.2016.03.003

25. Suzuki M, Takahashi S, Matsushima E, Tsunoda M, Kurachi M, Okada T, et al. Exploratory eye movement dysfunction as a discriminator for schizophrenia : a large sample study using a newly developed digital computerized system. Eur Arch Psychiatry Clin Neurosci (2009) 259:186-94. doi:10.1007/ s00406-008-0850-7

26. Levy DL, Sereno AB, Gooding DC, O'Driscoll GA. Eye tracking dysfunction in schizophrenia: characterization and pathophysiology. Curr Top Behav Neurosci (2010) 4:311-47. doi:10.1007/7854_2010_60

27. Krebs MO, Bourdel M-C, Cherif ZR, Bouhours P, Lôo H, Poirier MF, et al. Deficit of inhibition motor control in untreated patients with schizophrenia: further support from visually guided saccade paradigms. Psychiatry Res (2010) 179:279-84. doi:10.1016/j.psychres.2009.07.008

28. Caligiuri MP, Lohr JB. A disturbance in the control of muscle force in neuroleptic-naive schizophrenic patients. Biol Psychiatry (1994) 35:104-11. doi:10.1016/0006-3223(94)91199-1

29. Putzhammer A, Perfahl M, Pfeiff L, Ibach B, Johann M, Zitzelsberger U, et al. Performance of diadochokinetic movements in schizophrenic patients. Schizophr Res (2005) 79:271-80. doi:10.1016/j.schres.2005.05.020

30. Teremetz M, Amado I, Bendjemaa N, Krebs M-O, Lindberg PG, Maier MA. Deficient grip force control in schizophrenia: behavioral and modeling evidence for altered motor inhibition and motor noise. PLoS One (2014) 9:e111853. doi:10.1371/journal.pone.0111853

31. Sasayama D, Hori H, Teraishi T, Hattori K, Ota M, Matsuo J, et al. Benzodiazepines, benzodiazepine-like drugs, and typical antipsychotics impair manual dexterity in patients with schizophrenia. J Psychiatr Res (2014) 49:37-42. doi:10.1016/j.jpsychires.2013.10.019

32. Rosen AJ, Lockhart JJ, Gants ES, Westergaard CK. Maintenance of grip-induced muscle tension: a behavioral marker of schizophrenia. J Abnorm Psychol (1991) 100:583-93. doi:10.1037/0021-843X.100.4.583

33. Manschreck TC, Maher BA, Candela SF. Earlier age of first diagnosis in schizophrenia is related to impaired motor control. Schizophr Bull (2004) 30:351-60. doi:10.1093/oxfordjournals.schbul.a007084

34. Gschwandtner U, Pflüger M, Aston J, Borgwardt S, Drewe M, Stieglitz R-D, et al. Fine motor function and neuropsychological deficits in individuals at risk for schizophrenia. Eur Arch Psychiatry Clin Neurosci (2006) 256:201-6. doi:10.1007/s00406-005-0626-2

35. Manschreck TC, Chun J, Merrill AM, Maher BA, Boshes RA, Glatt SJ, et al. Impaired motor performance in adolescents at familial high-risk for schizophrenia. Schizophr Res (2015) 168:44-9. doi:10.1016/j.schres.2015.06.013

36. Millan MJ, Andrieux A, Bartzokis G, Cadenhead K, Dazzan P, Fusar-Poli P, et al. Altering the course of schizophrenia: progress and perspectives. Nat Rev Drug Discov (2016) 15:485-515. doi:10.1038/nrd.2016.28

37. Delevoye-Turrell Y, Giersch A, Danion J-M. Abnormal sequencing of motor actions in patients with schizophrenia: evidence from grip force adjustments during object manipulation. Am J Psychiatry (2003) 160:134-41. doi:10.1176/ appi.ajp.160.1.134

38. Lehoux C, Everett J, Laplante L, Emond C, Trépanier J, Brassard A, et al. Fine motor dexterity is correlated to social functioning in schizophrenia. Schizophr Res (2003) 62:269-73. doi:10.1016/S0920-9964(02)00327-4

39. Midorikawa A, Hashimoto R, Noguchi H, Saitoh O, Kunugi H, Nakamura K. Impairment of motor dexterity in schizophrenia assessed by a novel finger movement test. Psychiatry Res (2008) 159:281-9. doi:10.1016/j.psychres. 2007.04.004

40. Térémetz M, Colle F, Hamdoun S, Maier MA, Lindberg PG. A novel method for the quantification of key components of manual dexterity after stroke. J Neuroeng Rehabil (2015) 12:64. doi:10.1186/s12984-015-0054-0

41. Perlstein WM, Carter CS, Noll DC, Cohen JD. Relation of prefrontal cortex dysfunction to working memory and symptoms in schizophrenia. Am J Psychiatry (2001) 158(7):1105-13. doi:10.1176/appi.ajp.158.7.1105

42. American Psychiatric Association. Diagnostic and Statistical Manual of Mental Disorders. 4th ed. Washington, DC: American Psychiatric Press (2000).

43. Wykes T, Brammer M, Mellers J, Bray P, Reeder C, Williams C, et al. Effects on the brain of a psychological treatment: cognitive remediation therapy: functional magnetic resonance imaging in schizophrenia. Br JPsychiatry (2002) 181:144-52. doi:10.1192/bjp.181.2.144
44. Franck N, Duboc C, Sundby C, Amado I, Wykes T, Demily C, et al. Specific vs general cognitive remediation for executive functioning in schizophrenia: a multicenter randomized trial. Schizophr Res (2013) 147:68-74. doi:10.1016/j. schres.2013.03.009

45. Pillet B, Morvan Y, Todd A, Franck N, Duboc C, Grosz A, et al. Cognitive remediation therapy (CRT) benefits more to patients with schizophrenia with low initial memory performances. Disabil Rehabil (2015) 37:846-53. doi:10.3 109/09638288.2014.946153

46. Kay SR, Fiszbein A, Opler LA. The positive and negative syndrome scale (PANSS) for schizophrenia. Schizophr Bull (1987) 13:261-76. doi:10.1093/ schbul/13.2.261

47. Simpson GM, Angus JW. A rating scale for extrapyramidal side effects. Acta Psychiatr Scand Suppl (1970) 212:11-9. doi:10.1111/j.1600-0447.1970. tb02066.x

48. Brickenkamp R, Zillmer E. The D2 Test of Attention. Seattle, WA: Hogreffe and Huber Publishers (1998).

49. Wechsler D. WAIS-III: Wechsler Adult Intelligence Scale. Paris, France: Psychological Corporation (2000). Editions du Centre de Psychologie Appliquée.

50. Grant DA, Berg EA. A behavioral analysis of degree of reinforcement and ease of shifting to new responses in a Weigl-type card-sorting problem. J Exp Psychol (1948) 38:404-11. doi:10.1037/h0059831

51. Heaton R, Chelune G, Talley J, Kay G, Curtiss G. Wisconsin Card Sorting Test. Manual. Paris, France: Editions du Centre de Psychologie Appliquée (2002).

52. Krabbendam L, de Vugt ME, Derix MM, Jolles J. The behavioural assessment of the dysexecutive syndrome as a tool to assess executive functions in schizophrenia. Clin Neuropsychol (1999) 13(3):370-5. doi:10.1076/ clin.13.3.370.1739

53. Delis DC, Kaplan E, Kramer JH. DKEFS. San Antonio: Pearson (2001).

54. Trenerry M, Crosson B, DeBoe J, Leber W. The Stroop Neuropsychological Screening Test. Odessa, FL: Psychological Assessment Resources (1989).

55. Godefroy O. Fonctions exécutives et pathologies neurologiques et psychiatriques: Évaluation en pratique clinique. Marseille: De Boeck Supérieur (2008).

56. Harris JG, Minassian A, Perry W. Stability of attention deficits in schizophrenia. Schizophr Res (2007) 91(1-3):107-11. doi:10.1016/j. schres.2006.12.021

57. Hobart MP, Goldberg R, Bartko JJ, Gold JM. Repeatable battery for the assessment of neuropsychological status as a screening test in schizophrenia, II: convergent/discriminant validity and diagnostic group comparisons. Am J Psychiatry (1999) 156(12):1951-7.

58. McGrath J, Scheldt S, Welham J, Clair A. Performance on tests sensitive to impaired executive ability in schizophrenia, mania and well controls: acute and subacute phases. Schizophr Res (1997) 26(2-3):127-37. doi:10.1016/ S0920-9964(97)00070-4

59. Rodewald K, Rentrop M, Holt DV, Roesch-Ely D, Backenstrass M, Funke J, et al. Planning and problem-solving training for patients with schizophrenia: a randomized controlled trial. BMC Psychiatry (2011) 28(11):73. doi:10.1186/1471-244X-11-73

60. Keefe RS, Goldberg TE, Harvey PD, Gold JM, Poe MP, Coughenour L. The brief assessment of cognition in schizophrenia: reliability, sensitivity, and comparison with a standard neurocognitive battery. Schizophr Res (2004) 68(2-3):283-97. doi:10.1016/j.schres.2003.09.011

61. Amirjani N, Ashworth NL, Gordon T, Edwards DC, Chan KM. Normative values and the effects of age, gender, and handedness on the Moberg Pick-Up Test. Muscle Nerve (2007) 35:788-92. doi:10.1002/mus.20750

62. Benjamini Y, Hochberg Y. Controlling the False Discovery Rate: a practical and powerful approach to multiple testing. JR Stat Soc B (1995) 57:289-300.

63. Delevoye-Turrell Y, Giersch A, Wing AM, Danion J-M. Motor fluency deficits in the sequencing of actions in schizophrenia. JAbnorm Psychol (2007) 116:56-64. doi:10.1037/0021-843X.116.1.56

64. Kodama S, Fukuzako H, Fukuzako T, Kiura T, Nozoe S, Hashiguchi T, et al. Aberrant brain activation following motor skill learning in schizophrenic patients as shown by functional magnetic resonance imaging. Psychol Med (2001) 31:1079-88. doi:10.1017/S0033291701004196

65. Bombin I, Arango C, Buchanan RW. Significance and meaning of neurological signs in schizophrenia: two decades later. Schizophr Bull (2005) 31:962-77. doi:10.1093/schbul/sbi028 
66. Kasparek T, Rehulova J, Kerkovsky M, Sprlakova A, Mechl M, Mikl M. Cortico-cerebellar functional connectivity and sequencing of movements in schizophrenia. BMC Psychiatry (2012) 12:17. doi:10.1186/1471-244X-12-17

67. Bell MD, Lysaker PH, Milstein RM, Beam-Goulet JL. Concurrent validity of the cognitive component of schizophrenia: relationship of PANSS scores to neuropsychological assessments. Psychiatry Res (1994) 54:51-8. doi:10.1016/0165-1781(94)90064-7

68. Da Silva FN, Irani F, Richard J, Brensinger CM, Bilker WB, Gur RE, et al. More than just tapping: index finger-tapping measures procedural learning in schizophrenia. Schizophr Res (2012) 137:234-40. doi:10.1016/j. schres.2012.01.018

69. Horan WP, Green MF, Knowlton BJ, Wynn JK, Mintz J, Nuechterlein KH. Impaired implicit learning in schizophrenia. Neuropsychology (2008) 22:606-17. doi:10.1037/a0012602

70. Calkins ME, Tepper P, Gur RC, Ragland JD, Klei L, Wiener HW, et al. Project among African-Americans to explore risks for schizophrenia (PAARTNERS): evidence for impairment and heritability of neurocognitive functioning in families of schizophrenia patients. Am J Psychiatry (2010) 167:459-72. doi:10.1176/appi.ajp.2009.08091351

71. Greenwood TA, Braff DL, Light GA, Cadenhead KS, Calkins ME, Dobie DJ, et al. Initial heritability analyses of endophenotypic measures for schizophrenia: the consortium on the genetics of schizophrenia. Arch Gen Psychiatry (2007) 64:1242-50. doi:10.1001/archpsyc.64.11.1242

72. Docx L, Sabbe B, Provinciael P, Merckx N, Morrens M. Quantitative psychomotor dysfunction in schizophrenia: a loss of drive, impaired movement execution or both? Neuropsychobiology (2013) 68:221-7. doi:10.1159/000355293

73. Carroll CA, O'Donnell BF, Shekhar A, Hetrick WP. Timing dysfunctions in schizophrenia as measured by a repetitive finger tapping task. Brain Cogn (2009) 71:345-53. doi:10.1016/j.bandc.2009.06.009

74. Lang CE, Schieber MH. Reduced muscle selectivity during individuated finger movements in humans after damage to the motor cortex or corticospinal tract. J Neurophysiol (2004) 91:1722-33. doi:10.1152/jn.00805.2003

75. Forbes NF, Carrick LA, McIntosh AM, Lawrie SM. Working memory in schizophrenia: a meta-analysis. Psychol Med (2009) 39:889-905. doi:10.1017/ S0033291708004558

76. Hüttlova J, Kikinis Z, Kerkovsky M, Bouix S, Vu M-A, Makris N, et al. Abnormalities in myelination of the superior cerebellar peduncle in patients with schizophrenia and deficits in movement sequencing. Cerebellum (2014) 13:415-24. doi:10.1007/s12311-014-0550-y

77. Canu E, Agosta F, Filippi M. A selective review of structural connectivity abnormalities of schizophrenic patients at different stages of the disease. Schizophr Res (2015) 161:19-28. doi:10.1016/j.schres.2014.05.020

78. Whitty P, Clarke M, Browne S, McTigue O, Kamali M, Feeney L, et al. Prospective evaluation of neurological soft signs in first-episode schizophrenia in relation to psychopathology: state versus trait phenomena. Psychol Med (2003) 33:1479-84. doi:10.1017/S0033291703008225

79. Chan RCK, Geng F, Lui SSY, Wang Y, Ho KKY, Hung KSY, et al. Course of neurological soft signs in first-episode schizophrenia: relationship with negative symptoms and cognitive performances. Sci Rep (2015) 5:11053. doi:10.1038/ srep 11053

80. Avila MT, McMahon RP, Elliott AR, Thaker GK. Neurophysiological markers of vulnerability to schizophrenia: sensitivity and specificity of specific quantitative eye movement measures. J Abnorm Psychol (2002) 111:259-67. doi:10.1037/0021-843X.111.2.259

81. Benson PJ, Beedie SA, Shephard E, Giegling I, Rujescu D, St Clair D. Simple viewing tests can detect eye movement abnormalities that distinguish schizophrenia cases from controls with exceptional accuracy. Biol Psychiatry (2012) 72:716-24. doi:10.1016/j.biopsych.2012.04.019

82. Bachmann S, Degen C, Geider FJ, Schröder J. Neurological soft signs in the clinical course of schizophrenia: results of a meta-analysis. Front Psychiatry (2014) 5:185. doi:10.3389/fpsyt.2014.00185

Conflict of Interest Statement: MM and PL have a patent on the method for multidimensional measurement of manual dexterity (EP2659835A1) but do not own the commercialization rights. The other authors report no financial interests or potential conflicts of interest.

Copyright (C) 2017 Térémetz, Carment, Brénugat-Herne, Croca, Bleton, Krebs, Maier, Amado and Lindberg. This is an open-access article distributed under the terms of the Creative Commons Attribution License (CC BY). The use, distribution or reproduction in other forums is permitted, provided the original author(s) or licensor are credited and that the original publication in this journal is cited, in accordance with accepted academic practice. No use, distribution or reproduction is permitted which does not comply with these terms. 